\title{
EYE MOVEMENT DESENSITIZATION AND REPROCESSING (EMDR) UNTUK MENURUNKAN PTSD PADA KORBAN INSES
}

\author{
Dwi Sari Rizki*1, Khoirudin Bashori ${ }^{2}$, Elli Nur Hayati ${ }^{3}$ \\ Fakultas Psikologi Universitas Ahmad Dahlan \\ Jalan Kapas no 9 Semaki Yogyakarta 55166 \\ *dwisaririzki90@gmail.com
}

\begin{abstract}
Sexual violence against girlchild may trigger PTSD (post-traumatic stress disorder) which cause the individual feel helpless the whole life. This study aims to find out the effect of EMDR (Eye Movement Desensitization and Reprocessing) in reducing PTSD (post-traumatic stress disorder) suffered by a teen survivor of incest at YLPA (child protection agency foundation) of DIY (Yogyakarta special region). Subject of this study was17 years old girl who has PTSD symptoms as screened by the scale of IES$\mathrm{R}$ (Impact of event scale-Revised). Research carried out using a single case experimental design $(\mathrm{N}=1)$ with the design of the A-B-A-B with Follow Up. EMDR therapy was treated to the subject through a total of seven sessions. A qualitative interview and observation were also performed to capture the experience of the subject under the EMDR treatment. The results showed a decrease score of PTSD, as seen from the pretest (a score of 35), posttest (a scores of 4), and at the time of follow-up (a score of $3)$. That results were supported by interviews and observations that show the subject was able to manage her negative emotions and being able to control her selves when looking at objects that stimulate the trauma, and was able to find new positive beliefs. Based on these results, it is concluded that EMDR can decrease PTSD score suffered by victim of incestat YLPA DIY.
\end{abstract}

Keywords: emdr therapy, incest, ptsd

\begin{abstract}
Abstrak
Kekerasan seksual terhadap anak perempuan dapat memicu terjadinya PTSD (posttraumatic stress disorder) yang menyebabkan individu menjadi tidak berdaya seumur hidupnya. Penelitian ini bertujuan mengetahui pengaruh EMDR (Eye Movement Desensitization and Reprocessing)dalam menurunkan PTSD (post-traumatic stress disorder) yang diderita oleh seorang remaja putri korban inses yang didampingi oleh YLPA (Yayasan Lembaga Perlindungan Anak) DIY (Daerah Istimewa Yogyakarta). Subjek dalam penelitian ini yang mengalami PTSD adalah remaja puteri berusia 17 tahun dengan gejala PTSD sebagaimana diukur dengan IES-R (Impact of event scaleRevised). Penelitian ini dilakukan dengan desain eksperimen kasusu tunggal (single case experimental design) dengan desain A-B-A-B dan follow up. Wawancara dan observasi kualitatif juga dilakukan untuk melihat pengalaman subjektif subjek selama menjalani terapi EMDR. Perlakuan terapi EMDR dilaksanakan dalam tujuh sesi. Hasil penelitian menunjukkan menurunnya skor PTSD dari prates (skor 35), pascates (skor 4),
\end{abstract}


dan follow up (skor 3). Hasil wawancara dan observasi juga menunjukkan bahwa subjek telah dapat mengelola emosi negatifnya, dan dapat mengontrol dirinya sendiri ketika melihat objek yang menstimulasi traumanya, serta telah dapat menemukan keyakinan baru yang positif. Berdasarkan termuan tersebut maka dapat disimpulkan bahwa EMDR dapat menurunkan skor PTSD yang diderita oleh remaja putri korban inses di YLPA DIY.

Kata kunci: incest, ptsd, terapi emdr

\section{Pendahuluan}

Perempuan dan anak rawan menjadi objek tindak kekerasan di sekitar kita (Finkelhor,2010). Meskipun tindak kekerasan telah melanggar, menghambat dan mengabaikan hak asasi manusia, namun tindakan kekerasan tersebut terus terjadi di masyarakat. Kekerasan terhadap perempuan dan anak tidak saja menimbulkan dampak kesehatan fisik dan kesehatan reproduksi, namun juga dampak kesehatan mental (Krug, 2002). Dampak fisik mungkin dapat langsung ditandai dan nampak, namun dampak psikologis (mental)biasanya tidak mudah dilihat secara kasat matadan membutuhkan intervensi dari para professional baik di bidang kesehatan, psikologi, psikiatri, maupun di bidang hukum (Direktori Perlindungan Korban Kekerasan DIY, 2013).

Anak yang seharusnya mendapatkan perlindungan dan rasa aman dari orang dewasa kerap menjadi sasaran untuk pelampiasan kekerasan. Undang-Undang Perlindungan Anak (UU PA) nomor 35 Tahun 2014 (yang merupakan pengganti Undang-Undang nomor. 23 tahun 2002), menyatakan bahwa anak adalah seseorang yang belum berusia 18 tahun, termasuk anak yang masih dalam kandungan. Usia tersebut sangat rentan terhadap kekerasan dalam berbagai bentuk, yang meliputi kekerasan fisik, kekerasan emosi, kekerasan secara verbal dan kekerasan seksual (Finkelhor, 2010). Kekerasan seksual terhadap anak didefinisikan dalam Pasal 1 Ayat 4, Permeneg PPPA 01/2010 sebagai:

"Kekerasan terhadap anak adalah setiap perbuatan terhadap anak yang berakibat timbulnya kesengsaraan atau penderitaan secara fisik, mental, seksual, psikologis, termasuk penelantaran dan perlakuan buruk yang mengancam integritas tubuh dan merendahkan martabat anak".

Kekerasan seksual merupakan kasus yang banyak dialami oleh anak, salah satunya adalah inses (incest), yaitu aktifitas seksual yang terjadi antar anggota keluarga sedarah (blood relations), atau dapat juga terjadi oleh mereka yang tinggal serumah seperti saudara tiri, anggota keluarga hasil adopsi, atau orang lain yang dipercaya di keluarga tersebut (Bittles, 2012). Berdasarkan catatan Pusat Data dan Informasi Komisi Nasional Perlindungan Anak Indonesia, tahun 2010 - 2014 terdapat sejumlah 21.869.797 kasus pelanggaran hak anak yang terjadi di 179 kabupatan dan kota yang tersebar di 34 Provinsi. Sejumlah dari 42-58\% pelanggaran hak anak di atas merupakan kejahatan seksual terhadap anak. Data kasus LPA DIY selama tahun 2015 mencatat bahwa hingga bulan November ada sebanyak 49 kasus anak yang dilaporkan telah mengalami kekerasan yang berbeda-beda, antara lain kekerasan seksual, pencurian, kekerasan fisik, pengasuhan yang kurang tepat, penelantaran, penculikan, bullying, dan 
kekerasan psikis. Beberapa dari jenis kasus yang dilaporkan, kekerasan seksual menjadi kasus yang paling banyak dialami, yaitu sejumlah 13 anak.

Menutut Romauli \& Vindari (2012), dampak yang ditimbulkan oleh inses pada anak adalah terbunuhnya jiwa. Luka jiwa yang ditimbulkan akibat inses tersebut akan dibawa oleh anak hingga dewasa, menjadi luka abadi yang sulit dihilangkan karena korban mengalami pasca trauma yang pahit. Dampak lainnya yang ditimbulkan oleh kekerasan seksual adalah korban dapat berubah kepribadiannya 180 derajat, dari yang sebelumnya periang menjadi pemurung, lesu dan kehilangan semangat hidup. Pada beberapa kasus, korban bahkan menjadi apatis dan menarik diri, melakukan perilaku agresif, liar dan sulit diatur (Finkelhor, 2010). Kessler (dalam Leitch, 2007) menjelaskan, meskipun setelah beberapa tahun, simptom-simptom dari peristiwa traumatis akan tetap ada dan tidak berkurang secara spontan. Reaksi-reaksi maladaptive yang berkelanjutan terhadap suatu pengalaman traumatis disebut dengan Gangguan stress pascatrauma (posttraumatic stress disorder) (Nevid, et al, 2003).

PTSD merupakan gangguan emosional yang menyebabkan distress yang bersifat relatif menetap yang terjadi dalam jangka waktu tertentu setelah individu menghadapi ancaman keadaan atau kejadian diluar normal (outisde normal experience) yang membuat individu merasa benar-benar tercekam dan tidak berdaya (Taylor, et al, 2003). PTSD adalah gejala yang dirasakan oleh korban yang merasa mengalami kembali kejadian traumatiknya dulu, sehingga bereaksi menghindari stimulus yang terkait, serta memiliki tingkat kewaspadaan yang tinggi. Gangguan emosional yang terjadi setelah serangan fisik seperti perkosaan, kecelakaan lalu lintas, bencana alam atau kematian mendadak atas orang yang dicintai dapat memunculkan timbulnya PTSD (Durand \& Barlow, 2006).

Beberapa perlakuan dapat digunakan untuk menangani pasien yang mengalami stres pasca trauma, salah satunya adalah EMDR. EMDR memadukan antara pergerakan mata, pengingatan kembali peristiwa traumatik, serta verbalization (Connor \& Butterfield, 2003). EMDR yang terdiri dari 8 sesi mencakup delapan tahapan sebagai berikut: tahap pertama yaitu client history and treatment planning, tahap kedua preparation, tahap ketiga adalah assessment, tahap keempat desensitization, tahap kelima adalah Installation, tahap keenam body scan, tahap ketujuah closure dan tahap yang kedelapan adalah melakukan reevaluation (Leeds, 2009).

Hal yang paling unik dari EMDR adalah terapis menginduksi gerakan mata dengan cepat pada klien selama proses menghilangkan suatu hal yang kompleks (desensitisasi; seperti imaginal eksposur) dan fase-fase penginstalan. Pada umumnya, proses gerakan mata diinduksi dengan memerintahkan klien untuk mengikuti jari terapis kemudian menggerakkannya dengan cepat dan pada keempat arah silang yang dapat dilihat oleh klien. Bentuk lain dari stimulus secara bergantian (ketukan) atau aktifitas (tapping/tepukan tangan) terkadang malah digunakan pada proses gerakan mata (Rauch \& Cahill, 2003).

Beberapa penelitian menemukan bahwa EMDR efektif untuk menurunkan PTSD. Adler \& Tapia (2009) dalam penelitiannya menemukan bahwa EMDR merupakan psikoterapi yang efektif untuk menangani kasus individual pada anak yang mengalami PTSD. Penelitian terhadap PTSD akibat kekerasan seksual juga ditemukan oleh Anna, et al (2014) yang memberikan EMDR untuk menurunkan PTSD pada korban perkosaan, Farkas, et al (2010) yang menemukan efektifitas EMDR/MASTR dalam menghilangkan trauma pada anak-anak di pusat pelayanan perlindungan anak. Ricci (2006) juga menggunakan EMDR untuk mengurangi reaktifitas trauma masa kecil 
yang diakibatkan oleh inses. Intervensi ini dilakukan untuk mengeksplorasi hubungan antara desensitisasi dan pengolahan ulang memori traumatis dan bagaimana korban dapat mengubah perilakunya.

Leitch (2007) menyatakan bahwa EMDR terbukti merupakan intervensi yang paling konsisten memberikan efek yang positif untuk mengatasi trauma. Berdasarkan uraian di atas, penelitian ini bertujuan untuk menguji efektifitas EMDR untuk menurunkan PTSD korban incest di YLPA DIY.

\section{Metode Penelitian}

Penelitian ini menggunakan pendekatan kuantitatif dengan desain eksperimen kasus tunggal (single-case experimental design) untuk mengevaluasi efek suatu perlakuan (intervensi) dengan kasus tunggal. Pendekatan kualitatif juga dilakukan menggunakan metode wawancara dan observasi untuk menggali efektifitas perlakuan dari dimensi kognitif dan afektif subjek selama menjalani perlakuan. Subjek dalam penelitian ini adalah perempuan usia remaja awal yang mengalami inses oleh orang terdekat (ayah kandung). Subjek penelitian ini direkrut dari YLPA DIY, atas persetujuan pihak keluarga untuk menjadi subjek penelitian ini. Penelitian diawali dengan pengukuran Impact of Event Scale-Revised (IES-R) untuk melihat tingkat PTSD yang dialami oleh subjek. Intervensi dilakukan dengan pemberian terapi _EMDR oleh Psikolog senior yang telah bersertifikat dalam terapi EMDR.

Ada sebanyak tujuh (7) sesi terapi yang diberikan sebagai paket perlakuan terhadap subjek, dengan teknik utama menggunakan BLS (bilateral stimulation) yaitu gerakan jari tangan untuk memandu gerakan mata secara terarah sebagai upaya merelokasi penyimpanan emosi dalam prosesor otak yang kompleks akibat peristiwa traumatis. Shapiro (2001) menjelaskan bahwa aktivitas elektrik yang tidak selaras di hemisphere otak merupakan unsur patogenik (mulanya terjadi gangguan) yang memunculkan PTSD. Terapi EMDR berproses mensinkronisasikan atau menyelaraskan aktivitas elektrik tersebut sehingga mengubah reaksi takut yang terkondisi pada pengalaman traumatis, menjadi sebuah pengalaman netral. Terapi EMDR juga medesensitisasikan (mengurangi kepekaan) ingatan traumatis melalui proses relaksasi dan restrukturisasi (merubah) pola pikir yang tersimpan dalam ingatan traumatis tersebut.

\section{Hasil Dan Pembahasan}

Hasil skor IES-R subjek adalah sebesar 35 (kategori sedang) pada saat pre-test, dan lalu berubah menjadi 7 (rendah) setelah diberikan teknik stabilisasi dalam tiga kali pertemuan. Apa yang dirasakan oleh subjek pada periode ini dapat dilihat dari pernyataannya sebagai berikut:

"saya merasa tenang setelah diberikan terapi kemaren, dan saya selalu latihan ketika di rumah waktu pagi dan malam hari sebelum tidur”.

Pada saat tiga minggu tidak dilakukan terapi atau diberhentikan sementara, subjek mengalami peningkatan dari skor sebelumnya menjadi 22 (kategori sedang), 
artinya pada saat terapi tidak diberikan, subjek mengalami peningkatan skor, tetapi tidak melebihi baseline nya. Pada tahapan ini subjek menjelaskan perasaan dan pikirannya sebagai berikut:

"saya akui tidak terlalu rutin dalam latihan stabilisasi karena menurut saya stabilisasi lebih enak jika dipandu terapis, dibanding melakukan sendiri mba”.

Setelah terapi diberikan kembali dan diukur saat pos-test, subjek kembali mengalami penurunan skor menjadi 4 (kategori rendah). Setelah satu minggu setelah terapi subjek di follow-up untuk melihat perubahan lebih lanjut terhadap efek dari terapi, diperoleh skor subjek sebesar 3 (kategori rendah).Subjek menceritakan keadaan dirinya pada tahap ini sebagai berikut:

"saya sekarang udah los mba, lebih tenang. Kemaren-kemaren saya masih memendam sendiri, ibu pasti gak tau apa yang saya rasakan. Tapi sekarang saya benar-benar los, mungkin karena udah diceritakan semuanya. Saya janji untuk membuat hidupku agar lebih baik lagi”.

Temuan ini menunjukkan bahwa subjek mengalami penurunan tingkat PTSD. Deskripsi statistik dari skor PTSD korban incest pada saat pre-test, post-test dan followup yang diperoleh tersaji pada tabel berikut:

Tabel 1.

Hasil Pengukuran Skala PTSD

\begin{tabular}{ccccc}
\hline Pre-test & Perlakuan & $\begin{array}{c}\text { Perlakuan } \\
\text { diberhentikan }\end{array}$ & Pos-test & Follow-up \\
\hline 35 & 7 & 22 & 4 & 3 \\
\hline
\end{tabular}

Berdasarkan data tersebut dapat disimpulkan bahwa terapi EMDR adalah efektif untuk menurunkan skor PTSD pada subjek. Setelah nilai pre-test, post-test dan followup diperoleh, maka untuk menguji hipotesis dilakukan analisis secara kuantitatif menggunakan teknik visual inspection. Langkahnya adalah dengan menampilkan dalam grafik skor PTSD fase awal (pre-test), selama terapi, fase pemberhentian sementara, fase setelah mendapatkan perlakuan (pos-test), dan fase follow-up. Skor yang diperoleh partisipan dapat dilihat dalam grafik berikut ini:

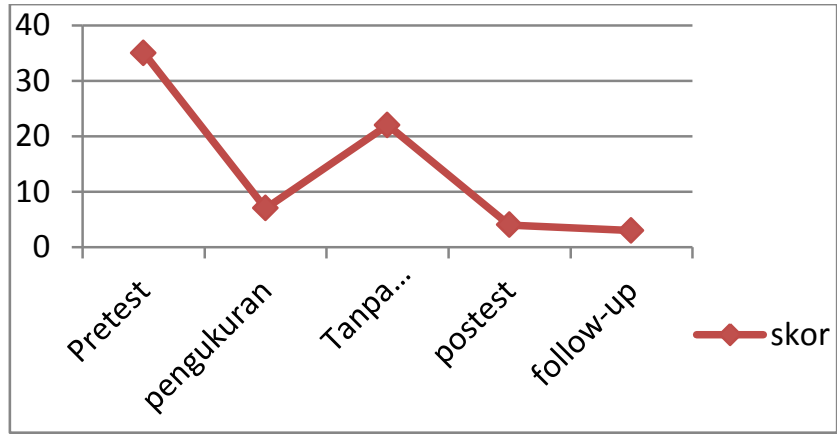

Grafik 1. Skor PTSD partisipan 
Hasil penelitian menunjukkan bahwa skor PTSD partisipan pada saat pre-test mendapatkan skor 35 (kategori sedang), setelah diberikan perlakuan berupa teknik stabilisasi subjek mengalami penurunan menjadi skor 7 (kategori rendah). Subjek kembali mengalami peningkatan skor menjadi 22 (kategori sedang) pada saat terapi dihentikan sementara waktu, namun setelah terapi dilanjutkan dan diberikan post-test, subjek kembali mengalami penurunan jumlah skor menjadi 4 (kategori rendah), selanjutnya setelah dilakukan follow-up subjek memperoleh skor menjadi 3 (kategori rendah).

Terapi EMDR terbukti dapat menurunkan tingkat PTSD yang dialami oleh partisipan. Pemberian terapi EMDR dapat membantu penderita PTSD dikarenakan cara kerjanya yang menurut (Shapiro, 2001), penggagas terapi EMDR, didasarkan pada sebuah konsep Adaptive Information Model. Teori model ini menjelaskan bahwa manusia diasumsikan memiliki sistem pemrosesan informasi inheren yang secara fisiologis dan neurobiologis menjadi alat untuk menyeimbangkan semua pemrosesan informasi. Setiap informasi tersimpan dalam sistem jaringan memori yang terstruktur secara neurobiologis, dimana dalam struktur neurobiologis ini tersimpan semua ingatan, pikiran, imajinasi, khayalan, emosi, dan sensasi. Selama proses adaptif yang normal, setiap informasi ditangkap oleh prosesor otak manusia dalam bentuk asosiasi yang tepat sehingga pengalaman digunakan secara konstruktif, dan proses belajar pun berjalan secara adaptif. Ketika seseorang mengalami persitiwa traumatik, terjadi kekacauan aktivitas elektrik yang tidak selaras di hemisphere otak sehingga memicu unsure patogenik yang memunculkan PTSD. Terapi EMDR berproses mensinkronisasikan atau menyelaraskan aktivitas elektrik tersebut sehingga mengubah reaksi takut yang terkondisi pada pengalaman traumatis, menjadi sebuah pengalaman netral sehingga distress emosional dapat tertangani dan diseimbangkan.

Sesuai dengan penemuan beberapa penelitian bahwa terapi EMDR ini berhasil dan efektif diberikan kepada korban incest. Allon (2015) pernah melakukan penelitian di Republik Demokratik Kongo mengenai efektifitas EMDR untuk para wanita korban kekerasan seksual (pemerkosaan) yang mederita PTSD. Hasil penelitiannya menunjukkan skala SUD (Subjective Units of Distress) mengalami penurunan yang signifikan dibandingkan peserta yang tidak diberikan terapi EMDR.

Sementara itu Ricci (2006) menggunakan EMDR untuk mengurangi reaktifitas trauma masa kecil yang diakibatkan oleh inces. Peneliti lain yaitu (Korn, 2009) juga menemukan bahwa EMDR mampu untuk mengobati kasus trauma incest pada anak. Terapi ini dilakukan untuk mengeksplorasi hubungan antara desensitisasi dan pengolahan ulang memori traumatis dan bagaimana korban dapat mengubah perilakunya. Penelitian ini juga menemukan bahwa EMDR efektif diberikan untuk korban inses.

Terapi EMDR juga telah berhasil merubah keyakinan negatif yang selama ini dimiliki subjek akibat perlakuan inses dari ayah kandungnya. Keyakinan itu adalah,

"aku merasa bersalah dengan kondisi ini, aku juga merasa tidak aman jika berada di dalam kamar, aku merasa takut dan selalu memeriksa kondisi kamar seperti pintu, jendela dan langit-langit kamar sebelum tidur. aku khawatir jika ternyata tiba-tiba ayahku keluar dari penjara dan menuju ke kamarku”.

Keyakinan tersebut selama ini telah menjadikan subjek untuk selalu merasa khawatir, cemas dan merasa takut jika sang ayah tiba-tiba keluar dari penjara dan 
kembali ke rumah lalu memasuki kamarnya lagi. Setelah menjalani 7 sesi terapi EMDR, keyakinan subjek mulai menunjukkan perubahan, seperti misalnya

"Aku merasa semakin nyaman, pada saat di dalam kamar aku merasa tidak takut lagi... karena aku sudah dapat menjaga diri dengan baik serta berani untuk melawan/ protes jika mendapatkan perlakuan yang tidak menyenangkan dari orang lain”.

Solomon dan Shapiro (2008) menyebutkan bahwa sikap, emosi dan sensasi bukanlah sebuah reaksi sederhana terhadap kejadian masa lalu; mereka itu adalah manifestasi dari berbagai persepsi yang tersimpan secara psikologis di dalam ingatan dan reaksi terhadap ingatan tersebut. Gejala perilaku buruk yang muncul saat ini merupakan aktifasi ingatan yang telah diproses secara tidak memadai sehingga menjadi sebuah keyakinan yang salah. EMDR berupaya untuk memproses ulang ingatan tersebut melalui cara stimulasi neurologis yang distimulasi sedemikian rupa agar mata seseorang mengikuti gerakan tangan yang teratur dari terapis, sehingga ingatannya dapat teproses dan tersimpan kembali secara memadai di dalam otak manusia (Solomon \& Shapiro, 2008).

\section{Simpulan}

Berdasarkan hasil penelitian yang telah dilakukan, maka dapat disimpulkan bahwa terapi EMDR efektif untuk menurunkan PTSD korban inses di YLPA DIY. Subjek dapat merasakan perubahan yang terjadi setelah mengikuti terapi EMDR. Selain itu perubahan yang terjadi juga terlihat dari skor PTSD yang mengalami penurunan dari pre-test mendapatkan skor 35 menjadi 4 pada saat post-test, dan setelah follow-up mengalami penurunan skor menjadi 3. Tingkat SUD terhadap peristiwa inses juga mengalami penurunan, dimana pada saat tahap baseline mendapat skala 6 , dan setelah intervensi EMDR menurun skornya menjadi 0, yang berarti pengalaman traumatik subjek telah dapat dikendalikan dengan baik.

\section{Daftar Pustaka}

Adler-Tapia,R., \& Settle, C.(2009). Evidence of the efficacy of EMDR with children and adolescents in individual psychotherapy: A review of the research published in peer-reviewed journals. Journal of EMDR Practice and Research, 3( 4), 242247.

Allon, M. (2015). EMDR group therapy with women who were sexually assaulted in the congo. Journal of EMDR Practice and Research, 9(1), 28-34.

Anna, T.M., Backstrom., Sondergaard., Torbjorn., Peter, H.Helstrom \& Lotti. (2014). Identifying risk factors for ptsd in women seeking medical help after rape. Plos One, 9(10), 1-9.

Bittles, A.H. (2012). Consanguinity in Context. London: Cambridge University Press.

Connor, K.M \& Butterfield, M.I. (2003). Posttraumatic stress disorder. Fokus The 
Journal of Lifelong Learning in Psychiatry, I(3),247-262.

Direktori Perlindungan Korban Kekerasan Daerah Istimewa Yogyakarta edisi ketiga. (2013). Forum perlindungan korban kekerasan DIY. Badan pemberdayaan perempuan dan masyarakat DIY.

Durand, V. M. \& Barlow, D. H.(2006). Psikologi abnormal. Yogyakarta: Pustaka Pelajar.

Farkas, L., Cyr, M., Lebeau, T.M., \& Lemay. J. (2010). Effectivenessof MASTR EMDR therapy for traumatized adolescents. Journal of Child \& Adolescent Trauma, 3(2), 125-142.

Finkelhor, D. Sexually Victimized Children. (2010). London: The Free Press.

Komnas Perlindungan Anak Indonesia, http://news.bisnis.com/read/20140519/79/229045/indonesia-darurat-kejahatanseksual-terhadap-anak (diakses pada April 2016).

Korn,D.L.(2009). EMDR and the treatment of complex PTSD:A review. Journal of EMDR Practice and Research, 3( 4), 264-278.

Krug, E.G., Dahlberg, L.L., Mercy, J.A., Zwi, A.B. and Lozano, R. (2002). World report onviolence and health. Geneva: WHO.

Leeds, A. M. (2009). A guide to the standard EMDR protocols forclinicians, supervisors, and consultants. New York: Springer Publishing Company.

Leitch,M.L.(2007).Somatic experiencing treatment with tsunami survivors inThailand: Broadening the scope of early intervention. Traumatology, 13(3), 11-20.

Nevid, J. S., Rathus, S.A., \& Greene, B. (2003). Psikologi abnormal. Jakarta: Penerbit Erlangga.

Rauch,S.A.M,Cahill, S.P.(2003). Treatment and prevention of posttraumatic stress disorder. Cinical Fokus Primary Psychiatry, 10(8), 60-65.

Ricci, R.J. (2006). Trauma resolution using eye movement desensitization and reprocessing with an incestuous sex offender. Clinical Case Studies, 5(3), 248265.

Romauli, S., \& Vindari, A.M. (2012). Kesehatan Reproduksi buat Mahasiswi Kebidanan. Yogyakarta: Nuha Medika.

Shapiro, F. (2001). Eye movement desensitization and reprocessing: Basic principles, protocols, and procedures, 2nd ed. New York: The Guilford Press.

Solomon, R.M., \&Shapiro, F. (2008). EMDR and the Adaptive Information Processing Model: Potential Mechanisms of Change. Journal of EMDR Practice and Research, 2(4), 315-325

Taylor, S., Thordarson, D.S., Fedoroff, I. C., Maxfield, L., Lovell, K., \& Ogrodniczuk, J. (2003). Comparative efficacy, speed and adverse effects of three PTSD 
treatments: Exposure therapy, EMDR and relaxation training. Journal of Consulting and Clinical Psychology, 71(2), 330-338. 